\title{
Sonographic Assessment of Renal Size in Healthy Adults
}

\author{
Wael El-Reshaid ${ }^{a}$ Husam Abdul-Fattah ${ }^{b}$ \\ ${ }^{a}$ Department of Medicine, Faculty of Medicine, Kuwait University, Safat, and ${ }^{\mathrm{b}}$ Division of Nephrology, \\ Al-Nafisi Dialysis Centre, Al-Sabah Hospital, Kuwait City, Kuwait
}

\section{Key Words}

Renal disease $\cdot$ Ultrasound $\cdot$ Renal length $\cdot$ Cortical thickness

\begin{abstract}
Objective: To assess the normal sonographic values of renal length and cortical thickness in healthy adults and establish reference ranges in our population for comparison when examining renal disease. Subjects and Methods: Sonographic assessment of renal length and cortical thickness were performed from January 2006 to December 2011 in 252 healthy individuals who were self-referred to the El-Reshaid Renal Clinic in Kuwait. They were screened for the absence of renal abnormalities. Weight and height were measured, and body mass index (BMI) and body surface area calculated. Patients were divided into 5 age groups: 18-30, 31-40, 41-50, 51-60 and $61-80$ years, in order to generate reference graphs for renal length and cortical thickness. Results: The mean renal lengths for the right and left kidney were $10.68 \pm 1.4$ and $10.71 \pm 1.0 \mathrm{~cm}$, respectively $(p=0.56)$ without a significant change with age. The minimum cortical thickness was 0.6 $\mathrm{cm}$. The renal length correlated with the weight of the patients $(p<0.01)$ and their BMI $(p<0.01)$ but not with their height. There was no difference in renal size or cortical thickness in patients older than 60 years despite an age-related
\end{abstract}

decline in the glomerular filtration rate $(p<0.001)$. Conclusions: Renal length and cortical thickness did not vary significantly with age. Renal length correlated well with weight and BMI but not with height. Hence, establishing normal ranges of renal parameters is essential for comparison in situations where possible renal disease is being investigated.

(c) 2014 S. Karger AG, Basel

\section{Introduction}

Measurement of renal size by ultrasound is essential when evaluating patients with possible renal disease. However, it requires prior knowledge of actual normal renal size in the population being studied. Renal ultrasound is simple, inexpensive and can be done at the bedside to provide the clinician with important anatomical details of the kidneys with a low interobserver variability [1-3]. It is also an essential procedure when performing renal biopsy in adults or children $[4,5]$, with both renal length and cortical thickness being important parameters that should be within normal limits before the procedure [6]. The safety of the diagnostic procedure using ultrasound is well established [7].

Dr. Wael El-Reshaid

Department of Medicine, Faculty of Medicine, Kuwait University PO Box 24923

Safat 13110 (Kuwait)

E-Mail albaderw@yahoo.com
This is an Open Access article licensed under the terms of th Creative Commons Attribution-NonCommercial 3.0 Unported license (CC BY-NC) (www.karger.com/OA-license), applicable to the online version of the article only. Distribution permitted for non-commercial purposes only. 
Fig. 1. Cortical thickness according to age showing mean with 10 and $90 \%$.

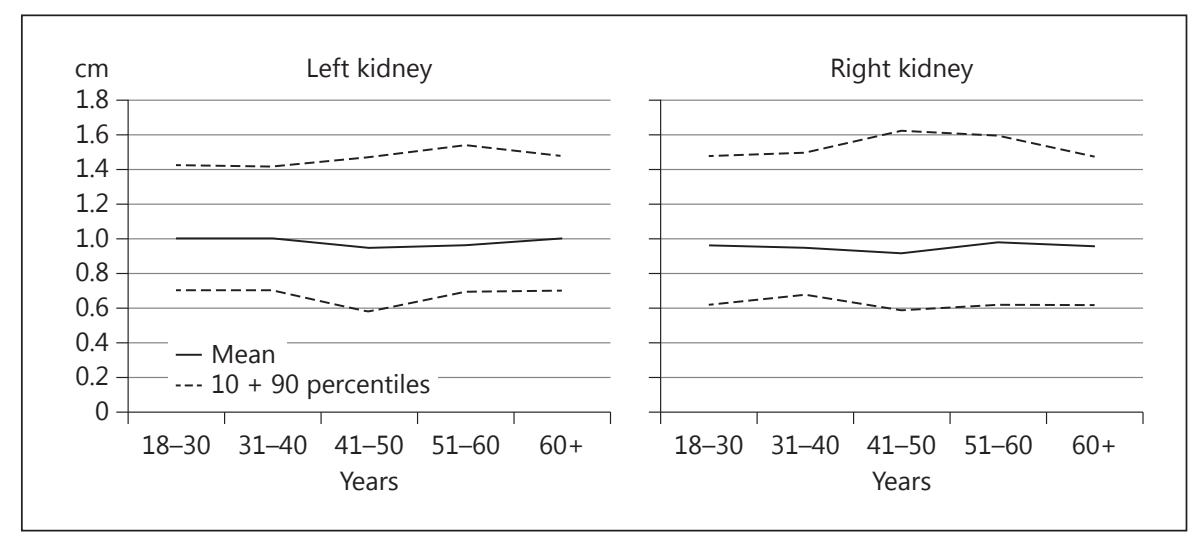

Renal length and cortical thickness have been studied extensively in animals and their parameters are well documented $[8,9]$. In humans, however, there have been only a few studies actually designed to measure these parameters in adults who do not have renal disease $[10,11]$. Unfortunately, in previous studies, some of the adults included had diseases such as diabetes and hypertension that could affect the kidneys [12]. Most also used serum creatinine alone as a measure of normal renal function without checking for urinary sediments and daily urinary protein excretion to rule out glomerular structural abnormalities [11, 12]. Serum creatinine is not an accurate estimate of kidney function and does not rule out the presence of renal disease even if it is within a normal range $[11,13]$. The objective of this study was to investigate the normal parameters of renal size and cortical thickness by ultrasound in individuals who have no renal disease and to establish the normal curves for these parameters on which comparisons can be made in situations where renal disease comes into question.

\section{Subjects and Methods}

The medical records of 477 patients aged 18-80 years for the period from January 2006 to December 2011 were reviewed at the El-Reshaid Renal Clinic, Kuwait, in order to exclude any disease that could affect renal length and cortical thickness. All the patients were asymptomatic at presentation. They had a normal serum creatinine level and normal calculated creatinine clearance using the Cockroft-Gault formula to establish the estimated glomerular filtration rate [14]. Abnormalities of the glomerular membrane such as proteinuria and hematuria were ruled out when normal urinary sediments and normal-range protein on 24-hour urine collection were reported. A general physical examination of all patients was performed including measurement of systolic and diastolic blood pressure. They were weighed on a digital scale while wearing an examination gown over underwear, and height was measured using a wall-mounted mechanical measuring rod with the patient standing barefoot. Body mass index (BMI) was calculated and body surface area (BSA) was obtained with the help of special charts using the weight and height of the patients. Exclusion criteria included diabetes in 108 patients, hypertension in 67, renal stones in 8 , renal scars in 6 , multiple cortical cysts in 3 , a single kidney in 2 , poor cortical visualization in 15 , increased cortical echogenicity in 5 and primary renal disease on screening tests in 19. A total of 252 healthy individuals (111 males and 141 females) were enrolled in the study after screening.

Digital renal ultrasound was performed with a LOGIQ C8 device (GE Healthcare, Milwaukee, Wisc., USA). The sonographic measurements included the longest longitudinal diameter (bipolar axis) and the cortical thickness of the kidney (the distance from the outer border of the renal cortex to the outer border of the medullary pyramid). In order to establish the standard normal reference values for renal length and cortical thickness, patients were stratified into 5 age groups: $18-30$ years $(n=87), 31-40$ years $(n=68)$, $41-50$ years $(\mathrm{n}=52), 51-60$ years $(\mathrm{n}=32)$ and $61-80$ years $(\mathrm{n}=13)$.

Analysis of the data was performed using the SPSS statistical package, version 17. Means for continuous variables were compared using the Student $t$ test. The differences between categorical variables were compared using the $\chi^{2}$ test. The Pearson correlation coefficient was used to test the significance of linear association between variables. $\mathrm{p}<0.05$ was considered significant. Normal graphs for population were created using means with 10 and $90 \%$ ( $95 \%$ confidence interval).

\section{Results}

The mean right and left renal lengths in our population were $10.68 \pm 1.4$ and $10.71 \pm 1.0 \mathrm{~cm}$, respectively, with a significant correlation ( $\mathrm{r}: 0.67, \mathrm{p}<0.001)$. The mean cortical thickness was $1.1 \pm 0.53 \mathrm{~cm}$ (range 0.60 1.61; fig. 1). Weight ranged from 37 to $124 \mathrm{~kg}$ while height ranged from 143 to $190 \mathrm{~cm}$. Renal length correlated sig- 


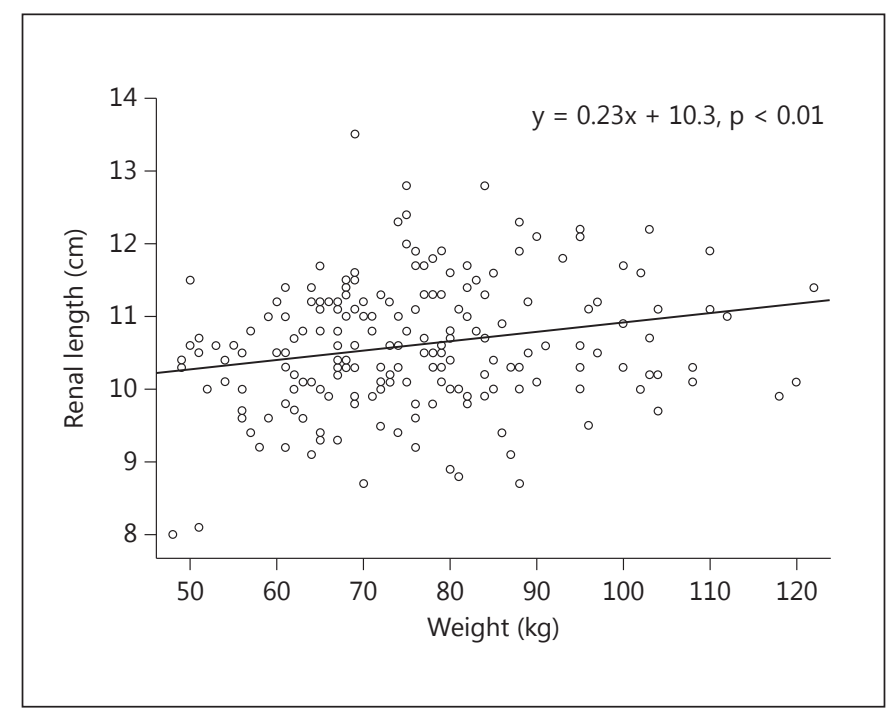

Fig. 2. The correlation between renal length and weight.

Table 1. Clinical and renal sonographic parameters in males and females

\begin{tabular}{lccc}
\hline Parameter & $\begin{array}{l}\text { Males } \\
(\mathrm{n}=111)\end{array}$ & $\begin{array}{l}\text { Females } \\
(\mathrm{n}=141)\end{array}$ & p value \\
\hline Age, years & $37.9 \pm 11.3$ & $37.6 \pm 13.6$ & n.s. \\
RK length, cm & $10.8 \pm 0.9$ & $10.5 \pm 1.1$ & n.s. \\
LK length, cm & $10.9 \pm 0.8$ & $11.2 \pm 0.9$ & n.s. \\
RCK, cm & $0.98 \pm 0.2$ & $0.98 \pm 0.8$ & n.s. \\
LCK, cm & $1.02 \pm 0.2$ & $1.02 \pm 0.6$ & n.s. \\
Weight, kg & $85 \pm 19$ & $70 \pm 14$ & $<0.0001$ \\
Height, cm & $172 \pm 6.5$ & $158 \pm 6.5$ & $<0.0001$ \\
BMI & $28.6 \pm 5.7$ & $28.2 \pm 6.1$ & n.s. \\
BSA, m ${ }^{2}$ & $2.01 \pm 0.24$ & $1.76 \pm 0.2$ & $<0.0001$ \\
CrCl, ml/min & $122 \pm 33$ & $122 \pm 33$ & n.s. \\
\hline
\end{tabular}

$\mathrm{CrCl}=$ Creatinine clearance; $\mathrm{LCK}=$ left cortical thickness; $\mathrm{LK}=$ left kidney; $\mathrm{RCK}$ = right cortical thickness; $\mathrm{RK}$ = right kidney; n.s. $=$ not significant.

nificantly with weight (Pearson: $0.57, \mathrm{p}<0.01$ ). Renal length increased by $0.23 \mathrm{~cm}$ for each $10-\mathrm{kg}$ increase in body weight within the range of $60-120 \mathrm{~kg}$ (fig. 2). Renal length, however, had no statistical correlation with height $(\mathrm{r}: 0.23, \mathrm{p}=0.46)$. BSA correlated with renal length (Pearson: $0.71, \mathrm{p}=0.02)$ with a significantly higher BSA in males than in females $(\mathrm{p}<0.001)$. The BMI showed a correlation that corresponded with renal length $(\mathrm{p}<0.005)$, as it is dependent on weight. Cortical thickness, however, did not show a similar correlation with weight or BMI ( $p=0.49$ and 0.94 , respectively). There was no difference between males and females in total renal length or cortical thickness (table 1).

There was a significant decline in creatinine clearance in subjects who were $>60$ years of age compared to those $<30$ years ( $100 \mathrm{vs.} 135 \mathrm{ml} / \mathrm{min}$, respectively, $\mathrm{p}<0.005$ ) but without a corresponding reduction in renal length (10.5 vs. $10.75 \mathrm{~cm}$, respectively, $\mathrm{p}=0.47$; table 2 ). Similarly, the reduction of cortical thickness with age was not statistically significant $(0.89 \mathrm{~cm}$ for individuals $>60$ years of age vs. $0.96 \mathrm{~cm}$ for those $<30$ years, $\mathrm{p}=0.23$ ). Hence, a reference graph for our population was generated to show the normal values for renal length and cortical thickness for both the right and left kidneys with a $95 \%$ confidence interval (fig. 3).

\section{Discussion}

This study of 252 healthy individuals of renal disease showed that a normal renal length is $10.67 \pm 1.4 \mathrm{~cm}$ and cortical thickness is $1.1 \pm 0.53 \mathrm{~cm}$ in our Kuwaiti population. The mean renal length in our study is similar to that reported for healthy Latin Americans and Nigerians (10 \pm 0.7 and $10.3 \pm 1.7 \mathrm{~cm}$, respectively) indicating an absence of disparity between renal size and ethnicity [15, 16]. The significant correlation between renal length and body weight was established in previous studies $[17,18]$. A probable explanation is based on Brenner's principle of right renal dosing which states that larger body size requires a larger nephron dose to meet its metabolic demands [19-21]. The finding that there is no difference in renal length between males and females in our study is consistent with other studies [22]. Some studies, however, show that renal length is greater in males than in females $[17,18]$. Gender difference is not significant if body weight and BSA are controlled for during statistical analysis. Height did not have an impact on renal size in our study, and the significant correlation between BMI and renal length was due to body weight.

Our finding of a cortical thickness of $0.6 \mathrm{~cm}$ was considered to be normal and is consistent with that reported by O'Neil [23]. Previous studies showed that cortical thickness is reduced in patients with a reduced glomerular filtration rate $[24,25]$. An age-related decline in renal function in elderly patients, considered normal by DOQI guidelines [26], did not have a significant impact on renal cortical thickness in our study [27]. Cortical thickness in 
Fig. 3. Reference graph for right and left renal sizes with age showing mean and 10 and $90 \%$.

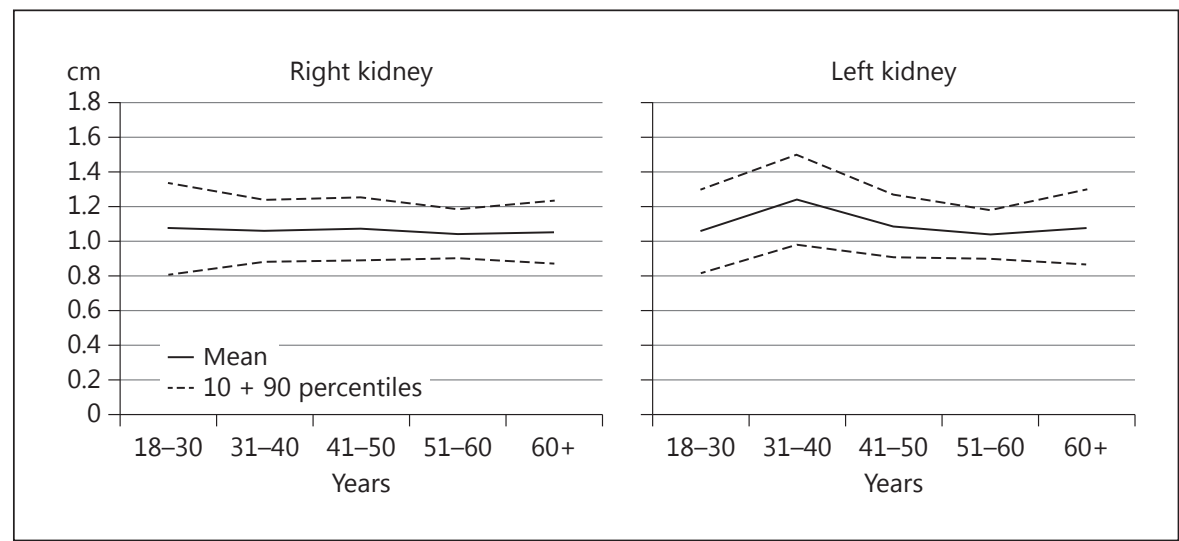

Table 2. Renal size and clinical parameters of different age groups

\begin{tabular}{lcccccc}
\hline Parameter & $\begin{array}{l}18-30 \text { years } \\
(\mathrm{n}=87)\end{array}$ & $\begin{array}{l}31-40 \text { years } \\
(\mathrm{n}=68)\end{array}$ & $\begin{array}{l}41-50 \text { years } \\
(\mathrm{n}=52)\end{array}$ & $\begin{array}{l}51-60 \text { years } \\
(\mathrm{n}=32)\end{array}$ & $\begin{array}{l}61-80 \text { years } \\
(\mathrm{n}=13)\end{array}$ & $\mathrm{p}$ value \\
\hline $\mathrm{RK}, \mathrm{cm}$ & $10.75 \pm 1.3$ & $10.6 \pm 0.9$ & $10.7 \pm 0.9$ & $10.4 \pm 0.7$ & $10.5 \pm 0.9$ & n.s. \\
$\mathrm{LK}, \mathrm{cm}$ & $10.6 \pm 1.2$ & $10.8 \pm 1.3$ & $10.9 \pm 0.9$ & $10.4 \pm 0.7$ & $10.8 \pm 1.1$ & n.s. \\
$\mathrm{RCK}, \mathrm{cm}$ & $0.96 \pm 0.2$ & $1.1 \pm 0.1$ & $0.92 \pm 0.2$ & $0.98 \pm 0.2$ & $0.89 \pm 0.2$ & n.s. \\
LCK, cm & $1.00 \pm 0.2$ & $1.00 \pm 0.2$ & $0.98 \pm 0.2$ & $0.95 \pm 0.2$ & $0.97 \pm 0.2$ & n.s. \\
Weight, kg & $70 \pm 16$ & $81 \pm 21$ & $80 \pm 22$ & $79 \pm 13$ & $83 \pm 15$ & $<0.01$ \\
Height, cm & $165 \pm 5$ & $166 \pm 9$ & $164 \pm 10$ & $163 \pm 10$ & $156 \pm 7$ & n.s. \\
BMI $\left(\mathrm{kg} / \mathrm{m}^{2}\right)$ & $25.7 \pm 4.9$ & $28.9 \pm 6.2$ & $29 \pm 6$ & $29.8 \pm 4$ & $33.9 \pm 6$ & n.s. \\
BSA, m ${ }^{2}$ & $1.8 \pm 0.2$ & $1.9 \pm 0.2$ & $1.9 \pm 0.3$ & $1.9 \pm 0.2$ & $1.9 \pm 0.2$ & n.s. \\
CrCl, ml/min & $135 \pm 32$ & $131 \pm 30$ & $116 \pm 27$ & $99.8 \pm 35$ & $100 \pm 21$ & $<0.001$ \\
Systolic BP, mm Hg & $120 \pm 9$ & $121 \pm 9$ & $122 \pm 11$ & $124 \pm 9$ & $130 \pm 9$ & $<0.01$ \\
Diastolic BP, mm Hg & $78 \pm 5$ & $79 \pm 6$ & $79 \pm 6$ & $79 \pm 6$ & $76 \pm 8$ & n.s. \\
\hline
\end{tabular}

$\mathrm{BP}=$ Blood pressure; $\mathrm{CrCl}=$ creatinine clearance; $\mathrm{LCK}=$ left cortical length; $\mathrm{LK}=$ left kidney length; n.s. = not significant; RCK = right cortical length; RK = right kidney length.

a recent study of monozygotic and dizygotic adult twins showed the negligible role of heritability and the important role of environment on renal parenchymal thickness [28]. The generation of reference graphs for normal renal length and cortical thickness in our Kuwaiti population could offer a comparison for future studies evaluating patients with renal abnormalities.

A limitation of this study was that there were fewer patients in the group aged $\geq 60$ years than in the other age groups. This did not impact significantly $(\mathrm{p}=0.27)$ on the results of the study, besides probably representing a normal age pyramid distribution, i.e. a wide base of individuals of a younger age and the older groups on the higher levels with fewer individuals.

\section{Conclusion}

This study has provided measurements of normal renal length and cortical thickness in the Kuwaiti population. We report a significant increase in renal length with patient weight and BMI but no similar increase was observed in cortical thickness. Increasing patient age or declining glomerular filtration rate, typically seen in elderly patients, did not correlate with a decrease in renal length or cortical thickness. 


\section{References}

1 Noble VE, Brown DF: Renal ultrasound. Emerg Med Clin North Am 2004;22:641-659.

$>2$ Rosenberg ER: Ultrasonographic evaluation of the kidney. Crit Rev Diagn Imaging 1982; 17:239-276.

-3 Emamian SA, Nielsen MB, Pedersen JF: Intraobserver and interobserver variations in sonographic measurements of kidney size in adult volunteers. A comparison of linear measurements and volumetric estimates. Acta Radiol 1995;36:399-401.

4 Sheikh M, Al-Essa A, Francis IP: Ultrasoundguided core biopsy of the kidneys in infants and children: Kuwait experience. Med Princ Pract 1999;8:213-216.

5 Agrawal PK, Rai HS, Amitabh V: Ultrasoundguided percutaneous renal biopsy. J Indian Med Assoc 1993;91:231-232.

-6 Jerassi R, Krusteva R, Kiperova B: Indications for renal biopsy in patients with renal failure based on ultrasound investigations. Int Urol Nephrol 1991;23:393-397.

7 Hergesell O, Felten H, Andrassy K, et al: Safety of ultrasound-guided percutaneous renal biopsy-retrospective analysis of 1,090 consecutive cases. Nephrol Dial Transplant 1998;13: 975-977.

$>8$ Debruyn K, Paepe D, Daminet S, et al: Renal dimensions at ultrasonography in healthy Ragdoll cats with normal kidney morphology: correlation with age, gender and bodyweight. J Feline Med Surg 2013;15:1046-1051.

$>9$ Draper AC, Bowen IM, Hallowell GD: Reference ranges and reliability of transabdominal ultrasonographic renal dimensions in thoroughbred horses. Vet Radiol Ultrasound 2012;53:336-341.
10 Sienz M, Ignee A, Dietrich CF: Sonography today: reference values in abdominal ultrasound: aorta, inferior vena cava, kidneys. $\mathrm{Z}$ Gastroenterol 2012;50:293-315.

-11 Barton EN, West WM, Sargeant LA, et al: A sonographic study of kidney dimensions in a sample of healthy Jamaicans. West Indian Med J 2000;49:154-162.

-12 Okoye IJ, Agwu KK, Eze CU: Relationship between sonographic renal length and renal parenchymal thickness in normal adult southeast Nigerians. West Afr J Med 2006;25:231234.

13 Cockcroft DW, Gault MH: Prediction of creatinine clearance from serum creatinine. Nephron 1976;16: 31-41.

14 O’Neill WC: Sonographic evaluation of renal failure. Am J Kidney Dis 2000;35:1021-1038.

15 Oyuela-Carrasco J, Rodríguez-Castellanos F, Kimura E, et al: Renal length measured by ultrasound in the adult Mexican population. Nefrologia 2009;29:30-34.

16 Okoye IJ, Agwu KK, Idigo FU: Normal sonographic renal length in adult south-east Nigerians. Afr J Med Med Sci 2005;34:129-131.

17 Buchholz NP, Abbas F, Biyabani SR, et al: Ultrasonographic renal size in individuals without known renal disease. J Pak Med Assoc 2000;50:12-16.

18 Wang F, Cheok SP, Kuan BB: Renal size in healthy Malaysian adults by ultrasonography. Med J Malaysia 1989;44:45-51.

19 Otiv A, Mehta K, Ali U, et al: Sonographic measurement of renal size in normal Indian children. Indian Pediatr 2012;49:533-536.
20 Brenner BM, Lawler EV, Mackenzie HS: The hyperfiltration theory: a paradigm shift in nephrology. Kidney Int 1996;49:1774-1777.

21 Luyckx VA, Brenner BM: Low birth weight, nephron number, and kidney disease. Kidney Int Suppl 2005;97:S68-S77.

22 Luyckx VA, Brenner BM: The clinical importance of nephron mass. J Am Soc Nephrol 2010;21:898-910.

23 O'Neill WC: Atlas of Renal Ultrasound. Philadelphia, Saunders, 2001, pp 17-49.

24 Mounier-Vehier C, Lions C, Devos P, et al: Cortical thickness: an early morphological marker of atherosclerotic renal disease. Kidney Int 2002;61:591-598.

25 Hirose K, Tsuchida H, Østerby R, et al: A strong correlation between glomerular filtration rate and filtration surface in diabetic kidney hyperfunction. Lab Invest 1980;43:434437.

26 KDOQI Clinical Practice Guidelines for Chronic Kidney Disease: Evaluation, Classification, and Stratification. Part 4: Definition and Classification of Stages of Chronic Kidney Disease. National Kidney Foundation.

27 Beland MD, Walle NL, Machan JT, et al: Renal cortical thickness measured at ultrasound: is it better than renal length as an indicator of renal function in chronic kidney disease? AJR Am J Roentgenol 2010; 195:W146-W149.

28 Tarnoki DL, Tarnoki AD, Littvay L, et al: Genetic and environmental variance of renal parenchymal thickness: a twin study. Croat Med J 2013;54:550-554. 